\title{
A diffusion tensor imaging study of structural dysconnectivity in never-medicated, first-episode schizophrenia
}

\author{
V. Cheung ${ }^{1}$, C. Cheung ${ }^{1}$, G. M. McAlonan ${ }^{1,2}$, Y. Deng ${ }^{1}$, J. G. Wong ${ }^{1}$, L. Yip ${ }^{3}$, K. S. Tai ${ }^{3}$, P. L. Khong ${ }^{2,3}$, \\ P. Sham ${ }^{1,2}$ and S. E. Chua ${ }^{1,2 *}$ \\ ${ }^{1}$ Department of Psychiatry, The University of Hong Kong, Pokfulam, S.A.R. China \\ ${ }^{2}$ State Key Laboratory for Brain and Cognitive Sciences, The University of Hong Kong, Pokfulam, S.A.R. China \\ ${ }^{3}$ Department of Radiology, Queen Mary Hospital, Pokfulam, S.A.R. China
}

Background. Diffusion tensor imaging (DTI) can be used to investigate cerebral structural connectivity in nevermedicated individuals with first-episode schizophrenia.

Method. Subjects with first-episode schizophrenia according to DSM-IV-R who had never been exposed to antipsychotic medication $(n=25)$ and healthy controls $(n=26)$ were recruited. Groups were matched for age, gender, best parental socio-economic status and ethnicity. All subjects underwent DTI and structural magnetic resonance imaging (MRI) scans. Voxel-based analysis was performed to investigate brain regions where fractional anisotropy (FA) values differed significantly between groups. A confirmatory region-of-interest (ROI) analysis of FA scores was performed in which regions were placed blind to group membership.

Results. In patients, FA values significantly lower than those in healthy controls were located in the left fronto-occipital fasciculus, left inferior longitudinal fasciculus, white matter adjacent to right precuneus, splenium of corpus callosum, right posterior limb of internal capsule, white matter adjacent to right substantia nigra, and left cerebral peduncle. ROI analysis of the corpus callosum confirmed that the patient group had significantly lower mean FA values than the controls in the splenium but not in the genu. The intra-class correlation coefficient (ICC) for independent ROI measurements was 0.90 (genu) and 0.90 (splenium). There were no regions where FA values were significantly higher in the patients than in the healthy controls.

Conclusions. Widespread structural dysconnectivity, including the subcortical region, is already present in neuroleptic-naive patients in their first episode of illness.

Received 20 April 2007; Revised 26 July 2007; Accepted 14 August 2007; First published online 22 October 2007

Key words: Diffusion, first episode, never medicated, schizophrenia, structural.

\section{Introduction}

The neurodevelopmental basis of schizophrenia refers to abnormal brain development before the onset of illness and is supported by compelling evidence of dysmaturation in the size of the brain (Wright et al. 2000), medial temporal lobe and hippocampi (Woodruff et al. 1997; Giedd et al. 1999), cerebral ventricular enlargement (Giedd et al. 1999; Woodruff et al. 1997), and less subcortical grey and white matter (see reviews by Wright et al. 2000 and Shenton et al. 2001).

Kanaan et al. (2005) recently reviewed the application of diffusion tensor imaging (DTI) to investigate

\footnotetext{
* Address for correspondence: Dr Siew-eng Chua, Department of Psychiatry Queen Mary Hospital, The University of Hong Kong, Pokfulam, Hong Kong.

(Email: sechua@hku.hk)
}

white matter structural integrity in schizophrenia. They observed that fractional anisotrophy (FA) was frequently reported to be decreased in patients compared to healthy controls, particularly in the corpus callosum (Foong et al. 2000, 2002; Ardekani et al. 2003; Hubl et al. 2004; Kalus et al. 2005), cingulum bundle (Kubicki et al. 2003, 2005; Sun et al. 2003; Hubl et al. 2004), striatum (Hubl et al. 2004; Kubicki et al. 2005; Szeszko et al. 2005), frontal and temporal gyri (Ardekani et al. 2003; Szeszko et al. 2005), arcuate fasciculi (Hubl et al. 2004; Kubicki et al. 2005) and hippocampal/parahippocampal region (Ardekani et al. 2003; Kalus et al. 2004, 2005). Other DTI-related studies of water diffusivity (Shin et al. 2006), grey matter (Rose et al. 2006) and symptom correlates (Hubl et al. 2004) also indicate disruption in frontotemporo-limbic microstructure in the disorder. Together with aberrant cortical cell migration in the 
prefrontal, anterior cingulate and entorhinal cortices (Benes, 1993; Eastwood \& Harrison, 2003), evidence of widespread regional dysconnectivity of the brain in schizophrenia is accumulating. However, Kanaan et al. (2005) added the important caveat that all DTI studies so far have involved neuroleptic-treated patients, small samples, and were methodologically heterogeneous. This could explain inconsistencies across studies (Steel et al. 2001; Foong et al. 2002; Price et al. 2005), making evaluation of larger numbers of neuroleptic-naive samples essential to definitively address the issue of white matter structural dysconnectivity in schizophrenia.

DTI detects brain structural changes overlooked on conventional magnetic resonance imaging (MRI) (Moseley, 2002) by measuring the degree of nonrandomness (FA) of water diffusion in the brain, from 0 (perfectly isotropic) to 1 (perfectly anisotropic) (Hoptmann et al. 2004). In healthy children, FA values increase in a region-specific manner in the brain and are related to childhood cognitive achievement (Deutsch et al. 2005; Schmithorst et al. 2005). Therefore, FA represents an innovative approach to evaluate the brain where region-specific dysmaturation is suspected. We recently reported generalized cerebral morphological abnormalities in grey and white matter and cerebrospinal fluid in never-medicated, firstepisode schizophrenia, with notable subcortical abnormalities in the brain (Chua et al. 2007). In the present study, we anticipated that DTI would demonstrate generalized structural dysconnectivity, including the subcortical region. We used a region-of-interest (ROI) analysis to independently confirm our method.

\section{Method}

\section{Subjects}

A consecutive series of patients presenting to our hospital were screened for eligibility to join the study. Inclusion criteria were: age 18-45 years; no previous antipsychotic treatment; first-ever experience of psychotic symptoms (i.e. hallucinations and/or delusions and/or thought disorder); no significant mood/organic disorder, with decline in daily functioning and fulfilling criteria for a diagnosis of DSM-IV schizophrenia (APA, 1994) after independent assessments by two specialists in psychiatry. Healthy controls from the local community were recruited by advertisement after screening for good physical health with no history of psychiatric or neurological disorder. Exclusion criteria were: any history of neurological problems; loss of consciousness; persistent headaches; head trauma; electroconvulsive therapy; psychostimulant use; history of neuroleptic use; and special school attendance. The study received the approval of the Institutional Review Board of the hospital. Patients were screened on the first day of presentation to hospital, and provided full informed written consent to participate. Symptoms were rated by a specialist psychiatrist with clinical responsibility for the care of the patients using the Positive and Negative Syndrome Scale (PANSS), a 30-item scale with positive, negative and general psychopathology items demonstrating high reliability and validity (Kay et al. 1987). Duration of psychosis was assessed by the Interview for the Retrospective Assessment of Schizophrenia (IRAOS; Hafner, 1992). According to clinical need, patients were prescribed the following medications as required: an anxiolytic (lorazepam $0.5 \mathrm{mg}$ bd prn) for agitation or a hypnotic (zopiclone $7.5 \mathrm{mg}$ nocte prn) for sleep. An MRI scan was performed according to the protocol below before initiating antipsychotic medication. We have successfully followed the patients who participated in the study for a minimum of 1 year and confirmed the diagnosis of schizophrenia.

\section{MRI data acquisition}

A GE Signa 1.5 T system (General Electric, Milwaukee, WI, USA) was used to acquire DTI and T2-weighted/ PD (proton density) datasets. A 5-min DTI sequence followed Leung et al. (2004) and comprised singleshot, spin-echo, echo-planar imaging with $\mathrm{TR}=$ $10000 \mathrm{~ms}, \mathrm{TE}=100 \mathrm{~ms}$, acquisition matrix $=128 \times 128$, and field of view $=28 \mathrm{~cm}$, slice thickness of $5 \mathrm{~mm}$ with a 1.5-mm gap. Diffusion-sensitizing gradient encoding (Basser et al. 1994; Basser, 1995) was applied in 25 directions using a diffusion-weighted factor $b=1200 \mathrm{~s} / \mathrm{mm}^{2}$, with one image, $b 0$ (non-diffusionweighted image), acquired without a diffusion gradient, $b=0 \mathrm{~s} / \mathrm{mm}^{2}$. Diffusion gradient directions were determined using minimal potential energy arrangements of points on a sphere (Hardin et al. 1997), and 26 images were obtained at each section yielding 468 or 494 images. A T2/PD sequence provided dual-echo, fast spin-echo data sets aligned to AC-PC across the whole brain, $3 \mathrm{~mm}$ thick, Nex =1, TR 5 s, TE 20/80 ms, matrix $256 \times 192$.

\section{Imaging processing and analysis}

FA maps for each subject were calculated according to the method of Basser \& Pierpaoli (1996) using DTIstudio (Radiology Department, Johns Hopkins University, USA). All subsequent image preprocessing and statistical manipulations were performed on SPM2 (Wellcome Department of Cognitive Neurology, Institute of Neurology, UK) running in MATLAB 6.5 (The MathWorks, Inc., Natick, MA, USA). 


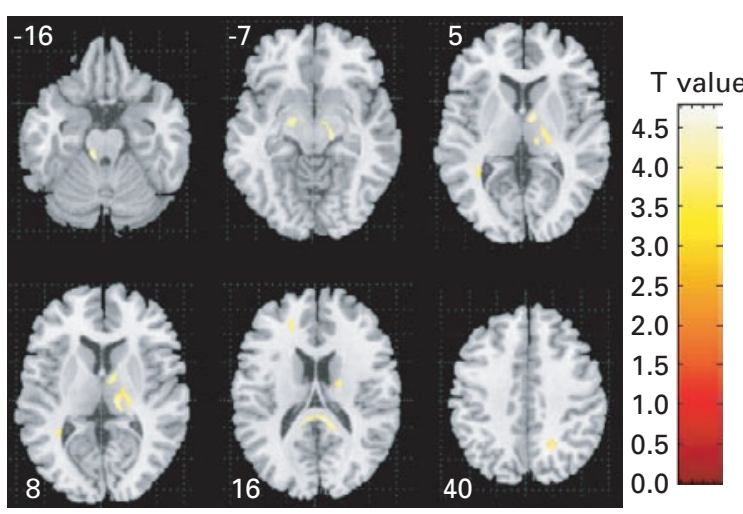

Fig. 1. Fractional anisotropy (FA) deficits in patients versus healthy controls. Relative deficit clusters (in yellow) in white matter FA in never-medicated patients with first-episode schizophrenia $(n=25)$ compared to controls $(n=26)$. The maps are orientated with the right side of the brain shown on the right side of the panel. The $z$ coordinate for each axial slice in the standard space of Talairach and Tournoux is given in millimetres.

Images were processed based on optimized voxelbased morphometry (VBM) methods (Basser \& Pierpaoli, 1996): first, a customized template of each brain tissue class was made by averaging linearly normalized, multi-spectral segmented T2 and PD weighted image pairs of all patients and controls, and smoothed with an 8-mm full-width half-maximum (FWHM) three-dimensional Gaussian kernel. Multispectral segmentation was used to enhance tissue classification accuracy (Styner et al. 2002). Second, the $b 0$ of each subject was segmented and spatially normalized (Ashburner \& Friston, 2000) to the custom template to correct for spatial distortion in the FA maps (Szeszko et al. 2005). As the current study focused on white matter, normalization parameters were determined by normalizing the white matter map to the custom white matter template (Specht et al. 2005). These transformation parameters were then applied to the FA maps so that the complete DTI dataset of each subject was transformed into MNI space (Hubl et al. 2004; Leung et al. 2004; Jones et al. 2005). All MNI coordinates were converted to Talairach using a standard non-linear algorithm (Brett, 2002). A white matter mask was used to limit the FA analysis to white matter only (Hubl et al. 2004; Leung et al. 2004; Szeszko et al. 2005) and the normalized FA maps were smoothed with a 6-mm FWHM Gaussian kernel for group comparison using a two-sample $t$ test. Contrasts were used to detect FA changes between patients and controls, and results were thresholded at false discovery rate (FDR)corrected $p<0.05$ (see Fig. 1 and Table 1). FDR is the proportion of false positives (incorrect rejections of the null hypothesis) among those tests for which the null hypothesis is rejected (Genovese et al. 2002). The FDR method is more appropriate to apply to neuroimaging data than the more conservative Bonferroni approach when group differences are likely to be present in multiple pixels (Genovese et al. 2002).

\section{Region-of-interest (ROI) analysis}

ROIs of radius $3 \mathrm{~mm}$ were placed on the FA map by an operator who was 'blind' to subject group membership. We selected ROIs on the corpus callosum as it is relatively easy to define and avoids the risk of contamination from the cerebrospinal fluid due to registration errors in voxel-base studies (Kanaan et al. 2005). The splenium was found post hoc to have significantly reduced FA in the patients from our voxel-based analysis, and the genu acted as a control ROI on the same principal interhemispheric tract. The first ROI for genu and splenium was placed $6 \mathrm{~mm}$ above the lowest (i.e. inferior-most) axial slice on the $z$ axis when the genu or the splenium was first barely seen. It was located at the midline of the genu or the splenium within the central boundary of the genu or splenium. The second ROI for genu and splenium was placed on the axial slice $6 \mathrm{~mm}$ above the first ROI, and also located in the midline and centrally within the boundaries of the genu or the splenium. Twenty-five patients and 26 healthy subjects were traced 'blind' to subject group membership. Ten randomly selected subjects' scans were also measured independently by another operator also 'blind' to subject group membership. The ICC for the ROIs was 0.90 for genu and 0.90 for splenium. Mean FA values within the ROIs were calculated by using dTV software (Masutani et al. 2003; Masutani, 2007) for between-group comparison (see Table 2).

\section{Results}

\section{Characteristics of the sample}

Of a total of 30 patients eligible to enter the study, four either declined or were not stable enough to participate in the opinion of their responsible clinician-in-charge. We recruited 26 healthy controls from the local community through advertisement. Thus, the final sample comprised 25 patients and 26 healthy controls, balanced on age (patients : mean $=28.5$ years, S.D. $=9.4$; controls: mean $=28.2$ years, S.D. $=9.2$; independent samples $t$ test, $p=0.90$, two-tailed), gender (13 male, 13 female patients; 11 male, 14 female controls, $\chi^{2}=0.206$, two-tailed), handedness (right-handed patients $87 \%$, right-handed controls $95 \%, \chi^{2}=0.135$, two-tailed) best paternal socio-economic status (SES) (patients mean value $=3.0$, s.D. $=1.2$; controls mean 
Table 1. Significant fractional anisotropy (FA) differences between patient and healthy control groups

\begin{tabular}{|c|c|c|c|c|c|c|c|c|}
\hline \multirow[b]{2}{*}{ Brain region } & \multirow{2}{*}{$\begin{array}{l}\text { Cluster } \\
\text { size } \\
\text { (voxel) }\end{array}$} & \multirow[b]{2}{*}{$\begin{array}{l}\text { Voxel } \\
p \text { value }^{*}\end{array}$} & \multicolumn{3}{|c|}{$\begin{array}{l}\text { Talairach coordinates } \\
(\mathrm{mm})\end{array}$} & \multirow[b]{2}{*}{$\begin{array}{l}\text { Voxel } \\
z \text { value }^{\mathrm{a}}\end{array}$} & \multicolumn{2}{|c|}{ Mean FA (S.D.) } \\
\hline & & & $\mathrm{x}$ & $\mathrm{y}$ & z & & $\begin{array}{l}\text { Controls } \\
(n=26)\end{array}$ & $\begin{array}{l}\text { Patients } \\
(n=25)\end{array}$ \\
\hline \multicolumn{9}{|l|}{ Frontal lobe } \\
\hline Left fronto-occipital fasciculus & 145 & 0.047 & -19 & 40 & 15 & 3.80 & $0.39(0.04)$ & $0.35(0.04)$ \\
\hline \multicolumn{9}{|l|}{ Temporal lobe } \\
\hline Left inferior longitudinal fasciculus & 140 & 0.047 & -34 & -45 & 9 & 3.69 & $0.48(0.04)$ & $0.44(0.04)$ \\
\hline \multicolumn{9}{|l|}{ Parietal lobe } \\
\hline Adjacent to right precuneus & 270 & 0.017 & 22 & -53 & 40 & 5.56 & $0.41(0.04)$ & $0.36(0.04)$ \\
\hline \multicolumn{9}{|l|}{ Subcortical regions } \\
\hline Right posterior limb of internal capsule & 381 & 0.047 & 10 & -3 & 5 & 4.38 & $0.41(0.02)$ & $0.38(0.03)$ \\
\hline Adjacent to right substantia nigra & 958 & 0.047 & 13 & -21 & -8 & 4.22 & $0.48(0.03)$ & $0.44(0.03)$ \\
\hline Right corpus callosum, splenium & 1141 & 0.047 & 8 & -35 & 18 & 4.31 & $0.63(0.05)$ & $0.57(0.04)$ \\
\hline \multicolumn{9}{|l|}{ Midbrain } \\
\hline Left cerebral peduncle & 436 & 0.001 & -8 & -31 & -16 & 4.24 & $0.48(0.05)$ & $0.42(0.03)$ \\
\hline
\end{tabular}

FDR, False discovery rate; S.D., standard deviation.

a All brain regions have their voxel $z$ value significant at the FDR-corrected level of 0.05 .

Table 2. ROI analysis by group: mean fractional anisotropy (FA) values for each group in the genu and splenium of the corpus callosum (CC)

\begin{tabular}{|c|c|c|c|c|c|c|c|}
\hline \multirow[b]{2}{*}{ ICC } & \multirow[b]{2}{*}{ Brain regions } & \multicolumn{2}{|c|}{$\begin{array}{l}\text { Patients }(n=25) \\
\text { Mean (s.D.) }\end{array}$} & \multicolumn{2}{|c|}{$\begin{array}{l}\text { Healthy controls }(n=26) \\
\text { Mean (S.D.) }\end{array}$} & \multirow[b]{2}{*}{$t$ value } & \multirow[b]{2}{*}{$p^{\mathrm{a}}$} \\
\hline & & ROI & TOI & ROI & TOI & & \\
\hline 0.90 & Genu of CC & $0.50(0.06)$ & $0.45(0.03)$ & $0.51(0.08)$ & $0.47(0.04)$ & $\begin{array}{l}\text { ROI } 0.9 \\
\text { TOI } 2.2\end{array}$ & $\begin{array}{l}1 \\
0.12\end{array}$ \\
\hline 0.90 & Splenium of CC & $0.64(0.07)$ & $0.50(0.03)$ & $0.72(0.08)$ & $0.54(0.04)$ & $\begin{array}{l}\text { ROI } 3.6 \\
\text { TOI } 3.8\end{array}$ & $\begin{array}{l}0.004^{*} \\
0.001^{*}\end{array}$ \\
\hline
\end{tabular}

ICC, Intra-class correlation coefficient; ROI, region of interest; TOI, target of interest.

ICC is also shown for independent ROI tracing 'blind' to group membership.

${ }^{a}$ Two-tailed significance, Bonferroni corrected.

* $p<0.005$.

value $=4.3$, S.D. $=3.5$, independent samples $t$ test, $p=0.20$, two-tailed) and ethnicity (all Chinese). For patients, PANSS positive symptom mean score $=$ 20.4, S.D. $=3.7$, PANSS negative symptom mean score $=14.6$, S.D. $=6.7$, PANSS general psychopathology mean score $=39.1$, S.D. $=10.7$. All patients were neuroleptic-naive and the median duration of untreated psychosis (DUP) was 180 days.

\section{Group differences in FA score}

FA values were significantly lower in the patients than in healthy controls in the left fronto-occipital fasciculus, left inferior longitudinal fasciculus, white matter adjacent to right precuneus, splenium of corpus callosum, right posterior limb of internal capsule, white matter adjacent to right substantia nigra, and left cerebral peduncle (voxel level significant at the FDR-corrected level of 0.05) (Fig. 1, Table 1). There were no regions where FA values were significantly higher in the patients than in the healthy controls.

\section{Discussion}

This is the first DTI study of white matter integrity in neuroleptic-naive patients, experiencing their first episode of schizophrenia. We found that FA values 
were significantly lower in patients than in healthy controls in the white matter of the following regions: left fronto-occipital fasciculus (adjacent to anterior cingulate gyrus, association tract linking orbital and lateral frontal cortices to occipital cortex), left inferior longitudinal fasciculus (adjacent to middle temporal gyrus, association tract linking occipital and temporal lobes), white matter adjacent to right precuneus, splenium of corpus callosum, right posterior limb of internal capsule, white matter adjacent to right substantia nigra, and left cerebral peduncle. There were no regions where FA values were significantly higher in the patients than in the healthy controls.

Our group differences largely concur with a recent comprehensive review (Kanaan et al. 2005) of 16 studies using DTI in schizophrenia patients, 14 of which reported reduced fractional anisotropy (i.e. FA or the degree to which diffusion of water is directionally hindered or anisotropic; Basser, 1995) in patients with schizophrenia. This was most commonly located in the white matter of the anterior cingulum and corpus callosum (Kanaan et al. 2005). When restricted to the five studies reviewed that used voxel-based analysis, other regions affected by schizophrenia included the white matter of the prefrontal cortex (Burns et al. 2003), middle and superior temporal gyrus (Ardekani et al. 2003; Szeszko et al. 2005), arcuate fasciculus (superior longitudinal fasciculus) (Burns et al. 2003), and uncinate fasciculus (anterior temporo-frontal fibre tracts) (Hubl et al. 2004); one study reported no differences (Foong et al. 2002). Our findings partly overlap with some recent voxel-based studies of DTI in schizophrenia that have confirmed reduced white matter connectivity in the fronto-temporo-parietal lobes and cerebral peduncle (midbrain) (Hao et al. 2006), and adjacent to the anterior cingulate cortex (Hao et al. 2006; Kumra et al. 2005). We note that direct comparison between different laboratories is limited when results are reported in grey matter rather than white matter terminology, partly because of the current lack of convention or the lack of an atlas displaying white matter tracts (Kanaan et al. 2005; Catani, 2006). In contrast to conventional MRI studies, which evaluate morphological change, diffusion-weighted scanning may present a more sensitive tool for determining individuals at risk for developing schizophrenia (DeLisi et al. 2006). However, it is important to note that all other DTI studies so far have evaluated chronic patients who have been exposed to years of neuroleptic treatment and these tended to identify widespread white matter association tract reduced FA such as in the arcuate fasciculus (superior longitudinal fasciculus that links perisylvian, frontal, parietal, temporal lobes) and uncinate fasciuli (connects orbito-frontal to anterior and medial temporal lobes) (Hubl et al. 2004; Catani \& ffytche, 2005; Kubicki et al. 2005). With regard to patients in their first episode of illness, a recent study of adults comprising a modest sample of 10 patients newly diagnosed with schizophrenia or schizo-affective disorder, most of whom had been medicated for a median of only 2 weeks (Szeszko et al. 2005), demonstrated internal capsular, frontal and superior temporal white matter lower FA than in healthy volunteers. From the same laboratory, a study of 26 children and adolescents with earlyonset schizophrenia who had been ill for some 2 years and were receiving maintenance neuroleptic treatment showed lower FA in the left anterior cingulate in the proximity of the left caudate nucleus (Kumra et al. 2005). These two studies indicate basal ganglia changes, which is of interest because our own neuroleptic-naive, first-episode sample also showed subcortical FA deficits (in addition to the more generalized abnormalities in cortico-cortical association and commissural tracts throughout the brain white matter). It is conceivable that lower subcortical FA values might represent a biomarker for illness onset or future relapse and we consider that this warrants a longitudinal study.

We found lower white matter 'connectivity' in the splenium of the corpus callosum of the patients. The corpus callosum is the principal interhemispheric white matter tract and myelinates rostro-caudally (Thompson et al. 2001) from birth to adolescence (Gilmore et al. 2004) in a linear fashion (Giedd et al. 1999), attenuating after puberty (Thompson et al. 2000). It surges in growth at around age 7 , and can be used to assess anomalous neurodevelopment in childhood (Giedd et al. 1999). The splenium connects homologous temporo-occipital cortices and showed lower FA in the patients, similar to previous work (Foong et al. 2000; Price et al. 2007). During neurodevelopment, the splenium has consistently higher FA values than, and myelinates before, the genu (Schneider et al. 2004), and our data might suggest early inefficiency in white matter connectivity between left and right temporo-occipital lobes.

We also identified decreased FA in the right substantia nigra, which is of importance, given the classical view that increased dopamine release from the midbrain can sensitize the prefrontal-limbic cortical targets to lead to psychosis (Laruelle, 2000). For the same reason, dopaminergic drugs for treatment of Parkinson's disease boost dopaminergic transmission in the nigro-striatal system, but unfortunately can induce psychosis (Rascol et al. 2003). Our finding of FA decrease in the left posterior limb of the internal capsule is close to that reported recently in the vicinity 
of the left caudate nucleus in minimally treated schizophrenia patients (Szeszko et al. 2005). The internal capsule abuts onto the basal ganglia, which are rich in dopamine receptors involved in antipsychotic response, so it would be reasonable to expect that local post-treatment change in interdendritic connections may also be associated with change in FA in this region. Furthermore, the posterior limb of the internal capsule connects the motor cortex by long association tracts to the cerebral peduncle, and it is therefore not surprising that FA in both regions is similarly decreased in our sample. Concerning the thalamus, it is a crucial gateway for sensory input to the cortex, and smaller thalamic volumes have been reported in schizophrenia (Andreasen et al. 1994; Gaser et al. 2004). It is thought to contribute to ventricular enlargement, which is already apparent in never-medicated patients in their first episode of psychosis (Chua et al. 2007).

We found lower FA in the left fronto-occipital fasciculus and left inferior longitudinal fasciculus. This suggests that patients have lower anteroposterior white matter connectivity between left orbito-frontal and left middle temporal cortices on the one hand, and the left occipital cortex on the other. This is compatible with the evidence of fronto-temporo-limbic disruption in the disorder (Weinberger \& Lipska, 1995; Ardekani et al. 2003). During normal development, FA increases during the second trimester of uterine life and is thought to correspond to neuronal migration from the germinal matrix (Gupta et al. 2005). It reaches near-adult white matter FA values by age 3, and stabilizes towards late adolescence (Schneider et al. 2004). Subsequently, the fronto-striatal maturation pattern is normal reduction in frontal lobe grey matter and increased myelination (Sowell et al. 1999). This suggests that risk of illness might be predicted by lower FA in the fronto-striatal regions (Sowell et al. 1999). Although these FA age-related changes reflect critical time periods prior to late adolescence, we think that they are not readily applicable to our own sample. Kumra et al. (2005) reported a subtle association of FA with age, but they studied adolescents who had been ill for 2 years and medicated. We have not identified a relationship between FA and age/duration of illness, possibly because FA tends to stabilize after late adolescence, or because of sample size. We believe that a neurodevelopmental interpretation cannot be made, but our study is valuable because it is the first to show widespread FA deficits independent of chronicity and medication, and this might lend tentative support to a disconnectivity theory of schizophrenia (Bullmore et al. 1998; Wright et al. 1999).

\section{Strengths and weaknesses of study}

We recruited patients who had been carefully diagnosed and closely ethnically and demographically balanced with the healthy controls. The major strength of our study was that all our patients were neuroleptic-naive and experiencing their first episode of psychosis. Therefore, the results from studies incorporating more chronically ill patients in receipt of antipsychotic treatment, or those with an admixture of neuroleptic-naive and neuroleptic-treated patients, may well differ from ours. We also screened out drug abuse and excluded patients younger than 18. This may explain why our patients were some years older than other first-episode psychotic populations and had been ill for about 1 year. Although there was no significant intergroup difference in sex, and the number of females was similar between the groups, there was a slight excess of healthy control females in our sample. Females are more likely to have increased left-sided frontal asymmetry with higher FA values (Szeszko et al. 2003). Thus, having fewer females in the schizophrenia group could indirectly accentuate any left-sided frontal deficits in FA value. However, we did not observe any left frontal asymmetry in FA value in the voxel-based results, nor in the ROI analysis, which showed no group difference in FA values in the genu of the corpus callosum. Accordingly, we do not think that the between-group sex difference was a substantial confounder of our findings. Finally, we adopted a voxel-based approach not constrained by prior hypotheses and included an ROI analysis of the genu and splenium of the corpus callosum as a post hoc confirmatory analysis and also because this is a readily traceable and prime inter-hemispheric tract. At the time of study commencement, the DTI sequence used relatively thick, non-contiguous slices and for the sake of data continuity this protocol remained throughout the sample acquisition. Partial volume artefacts can arise from this, and other inherent methodological problems in the DTI voxel-based approach [e.g. heterogeneity of white matter FA from differential tract coherence and spatial registration problems adjacent to the ventricles (Leung et al. 2004), relatively poor spatial resolution, and smoothing filter size differences (Jones et al. 2005)], can also contribute to pre-processing and interpretation challenges. To limit these problems, we confined our analysis to the area delineated by the white matter (WM) mask, and we used a relatively small filter size $(6 \mathrm{~mm})$, which has been reported to be helpful in reducing the likelihood of false-positive results (Jones et al. 2005). The future plan is to repeat the DTI scan after antipsychotic treatment to evaluate brain connectivity changes and determine whether 
this can assist in the prediction of early treatment response.

In conclusion, DTI represents a useful new tool to assess the brain in schizophrenia. We have found that evaluation of white matter connectivity early in the illness and before drug treatment commences suggests that schizophrenia is associated with significant FA decrease throughout the brain, including the subcortical region. In a future extension of this study, we plan to examine post-treatment brain changes and outcome. We hope that DTI might eventually provide a potentially useful tool to predict early outcome or even guide treatment choices in newly psychotic patients.

\section{Acknowledgements}

This work was supported by a research grant to Dr Chua from the CRCG, the University of Hong Kong. We thank our colleagues for assistance in subject recruitment. We thank M. K. Leung for her assistance with the ROI measurements.

\section{Declaration of Interest}

None.

\section{References}

Andreasen NC, Arndt S, Swayze V, Cizadlo T, Flaum M, O'Leary D, Ehrhardt JC, Yuh WT (1994). Thalamic abnormalities in schizophrenia visualized through magnetic resonance image averaging. Science 266, 294-298.

APA (1994). Diagnostic and Statistical Manual of Mental Disorders. American Psychiatric Association: Washington, DC.

Ardekani BA, Nierenberg J, Hoptman MJ, Javitt DC, Lim KO (2003). MRI study of white matter diffusion anisotropy in schizophrenia. Neuroreport 14, 2025-2029.

Ashburner J, Friston KJ (2000). Voxel-based morphometry: the methods. Neuroimage 11, 805-821.

Basser PJ (1995). Inferring microstructural features and the physiological state of tissues from diffusion-weighted images. Nuclear Magnetic Resonance in Biomedicine 8, 333-344.

Basser PJ, Mattiello J, LeBihan D (1994). MR diffusion tensor spectroscopy and imaging. Biophysics Journal 66, 259-267.

Basser PJ, Pierpaoli C (1996). Microstructural and physiological features of tissues elucidated by quantitative-diffusion-tensor MRI. Journal of Magnetic Resonance B 111, 209-219.

Benes FM (1993). The relationship between structural brain imaging and histopathologic findings in schizophrenia research. Harvard Review of Psychiatry 1, 100-109.

Brett M (2002). The MNI Brain and the Talairach Atlas. MRC Cognition and Brain Sciences Unit: Cambridge.
Bullmore ET, Woodruff PWR, Wright IC, Rabe-Hesketh S, Howard RJ, Shuriquie N, Murray RM (1998). Does dysplasia cause anatomical dysconnectivity in schizophrenia? Schizophrenia Research 30, 127-135.

Burns J, Job D, Bastin ME, Whalley H, Macgillivray T, Johnstone EC, Lawrie SM (2003). Structural disconnectivity in schizophrenia: a diffusion tensor magnetic resonance imaging study. British Journal of Psychiatry 182, 439-443.

Catani M (2006). Diffusion tensor magnetic resonance imaging tractography in cognitive disorders. Current Opinion in Neurology 19, 599-606.

Catani M, ffytche DH (2005). The rises and falls of disconnection syndromes. Brain 128, 2224-2239.

Chua SE, Cheung C, Cheung V, Tsang JT, Chen EY, Wong JC, Cheung JP, Yip L, Tai KS, Suckling J, McAlonan GM (2007). Cerebral grey, white matter and CSF in never-medicated, first-episode schizophrenia. Schizophrenia Research 89, 12-21.

DeLisi LE, Szulc KU, Bertisch H, Majcher M, Brown K, Bappal A, Branch CA, Ardekani BA (2006). Early detection of schizophrenia by diffusion weighted imaging. Psychiatry Research 148, 61-66.

Deutsch GK, Dougherty RF, Bammer R, Siok WT, Gabrieli JD, Wandell B (2005). Children's reading performance is correlated with white matter structure measured by diffusion tensor imaging. Cortex 41, 354-363.

Eastwood SL, Harrison PJ (2003). Interstitial white matter neurons express less reelin and are abnormally distributed in schizophrenia: towards an integration of molecular and morphologic aspects of the neurodevelopmental hypothesis. Molecular Psychiatry 8, 769, 821-831.

Foong J, Maier M, Clark CA, Barker GJ, Miller DH, Ron MA (2000). Neuro-pathological abnormalities of the corpus callosum in schizophrenia: a diffusion tensor imaging study. Journal of Neurology, Neurosurgery and Psychiatry 68, 242-244.

Foong J, Symms MR, Barker GJ, Maier M, Miller DH, Ron MA (2002). Investigating regional white matter in schizophrenia using diffusion tensor imaging. Neuroreport 13, 333-336.

Gaser C, Nenadic I, Buchsbaum BR, Hazlett EA, Buchsbaum MS (2004). Ventricular enlargement in schizophrenia related to volume reduction of the thalamus, striatum, and superior temporal cortex. American Journal of Psychiatry 161, 154-156.

Genovese CR, Lazar NA, Nichols T (2002). Thresholding of statistical maps in functional neuroimaging using the false discovery rate. Neuroimage 15, 870-878.

Giedd JN, Blumenthal J, Jeffries NO, Rajapakse JC, Vaituzis AC, Liu H, Berry YC, Tobin M, Nelson J, Castellanos FX (1999). Development of the human corpus callosum during childhood and adolescence: a longitudinal MRI study. Progress in Neuropsychopharmacology and Biological Psychiatry 23, 571-588.

Gilmore JH, Zhai G, Wilber K, Smith JK, Lin W, Gerig G (2004). 3 Tesla magnetic resonance imaging of the brain in newborns. Psychiatry Research 132, 81-85. 
Gupta RK, Hasan KM, Trivedi R, Pradhan M, Das V, Parikh NA, Narayana PA (2005). Diffusion tensor imaging of the developing human cerebrum. Journal of Neuroscience Research 81, 172-178.

Hafner HR (1992). IRAOS: an instrument for the assessment of the onset and early course of schizophrenia.

Schizophrenia Research 6, 209-223.

Hao Y, Liu Z, Jiang T, Gong G, Liu H, Tan L, Kuang F, Xu L, Yi Y, Zhang Z (2006). White matter integrity of the whole brain is disrupted in first-episode schizophrenia. Neuroreport 17, 23-26.

Hardin RH, Sloane NJA, Smith WD (1997). Minimal Energy Arrangements of Points on a Sphere (www.research.att.com/ $\sim$ njas/electrons/). Accessed 26 July 2007.

Hoptman MJ, Ardekani BA, Butler PD, Nierenberg J, Javitt DC, Lim KO (2004). DTI and impulsivity in schizophrenia: a first voxelwise correlational analysis. Neuroreport 15, 2467-2470.

Hubl D, Koenig T, Strik W, Federspiel A, Kreis R, Boesch C, Maier SE, Schroth G, Lovblad K, Dierks T (2004). Pathways that make voices: white matter changes in auditory hallucinations. Archives of General Psychiatry 61, 658-668.

Jones DK, Symms MR, Cercignani M, Howard RJ (2005). The effect of filter size on VBM analyses of DT-MRI data. Neuroimage 26, 546-554.

Kalus P, Buri C, Slotboom J, Gralla J, Remonda L, Dierks T, Strik WK, Schroth G, Kiefer C (2004). Volumetry and diffusion tensor imaging of hippocampal subregions in schizophrenia. Neuroreport 15, 867-871.

Kalus P, Slotboom J, Gallinat J, Federspiel A, Gralla J, Remonda L, Strik WK, Schroth G, Kiefer C (2005). New evidence for involvement of the entorhinal region in schizophrenia : a combined MRI volumetric and DTI study. Neuroimage 24, 1122-1129.

Kanaan RA, Kim JS, Kaufmann WE, Pearlson GD, Barker GJ, McGuire PK (2005). Diffusion tensor imaging in schizophrenia. Biological Psychiatry 58, 921-929.

Kay SR, Fiszbein A, Opler LA (1987). The positive and negative syndrome scale (PANSS) for schizophrenia. Schizophrenia Bulletin 13, 261-276.

Kubicki M, Park H, Westin CF, Nestor PG, Mulkern RV, Maier SE, Kikinis R, Jolesz FA, McCarley RW, Shenton ME (2005). DTI and MTR abnormalities in schizophrenia: analysis of white matter integrity. Neuroimage 26, 1109-1118.

Kubicki M, Westin CF, Nestor PG, Wible CG, Frumin M, Maier SE, Kikinis R, Jolesz FA, McCarley RW, Shenton ME (2003). Cingulate fasciculus integrity disruption in schizophrenia: a magnetic resonance diffusion tensor imaging study. Biological Psychiatry 54, 1171-1180.

Kumra S, Ashtari M, Cervellione KL, Henderson I, Kester H, Roofeh D, Wu J, Clarke T, Thaden E, Kane JM, Rhinewine J, Lencz T, Diamond A, Ardekani BA Szeszko PR (2005). White matter abnormalities in early-onset schizophrenia: a voxel-based diffusion tensor imaging study. Journal of the American Academy of Child and Adolescent Psychiatry 44, 934-941.
Laruelle M (2000). The role of endogenous sensitization in the pathophysiology of schizophrenia: implications from recent brain imaging studies. Brain Research Reviews 31, 371-384.

Leung LH, Ooi GC, Kwong DL, Chan GC, Cao G, Khong PL (2004). White-matter diffusion anisotropy after chemoirradiation: a statistical parametric mapping study and histogram analysis. Neuroimage 21, 261-268.

Masutani Y (2007). Diffusion Tensor Visualizer Version II (www.ut-radiology.umin.jp/people/masutani/dTV.htm). Accessed 26 July 2007.

Masutani Y, Aoki S, Abe O, Hayashi N, Otomo K (2003). MR diffusion tensor imaging: recent advance and new techniques for diffusion tensor visualization. European Journal of Radiology 46, 53-66.

Moseley M (2002). Diffusion tensor imaging and aging: a review. Nuclear Magnetic Resonance in Biomedicine 15, 553-560.

Price G, Bagary MS, Cercignani M, Altmann DR, Ron MA (2005). The corpus callosum in first episode schizophrenia: a diffusion tensor imaging study. Journal of Neurology, Neurosurgery and Psychiatry 76, 585-587.

Price G, Cercignani M, Parker GJ, Altmann DR, Barnes TR, Barker GJ, Joyce EM, Ron MA (2007). Abnormal brain connectivity in first-episode psychosis: a diffusion MRI tractography study of the corpus callosum. Neuroimage 35, 458-466.

Rascol O, Payoux P, Ory F, Ferreira JJ, Brefel-Courbon C, Montastruc JL (2003). Limitations of current Parkinson's disease therapy. Annals of Neurology 53 (Suppl. 3), S3-S12.

Rose SE, Chalk JB, Janke AL, Strudwick MW, Windus LC, Hannah DE, McGrath JJ, Pantelis C, Wood SJ, Mowry BJ (2006). Evidence of altered prefrontal-thalamic circuitry in schizophrenia: an optimized diffusion MRI study. Neuroimage 32, 16-22.

Schmithorst VJ, Wilke M, Dardzinski BJ, Holland SK (2005). Cognitive functions correlate with white matter architecture in a normal pediatric population: a diffusion tensor MRI study. Human Brain Mapping 26, 139-147.

Schneider JF, Il'yasov KA, Hennig J, Martin E (2004). Fast quantitative diffusion-tensor imaging of cerebral white matter from the neonatal period to adolescence. Neuroradiology 46, 258-266.

Shenton ME, Dickey CC, Frumin M, McCarley RW (2001). A review of MRI findings in schizophrenia. Schizophrenia Research 49, 1-52.

Shin YW, Kwon JS, Ha TH, Park HJ, Kim DJ, Hong SB, Moon WJ, Lee JM, Kim IY, Kim SI, Chung EC (2006). Increased water diffusivity in the frontal and temporal cortices of schizophrenic patients. Neuroimage 30, 1285-1291.

Sowell ER, Thompson PM, Holmes CJ, Jernigan TL, Toga AW (1999). In vivo evidence for post-adolescent brain maturation in frontal and striatal regions. Nature Neuroscience 2, 859-861.

Specht K, Minnerop M, Muller-Hubenthal J, Klockgether T (2005). Voxel-based analysis of multiple-system atrophy of cerebellar type: complementary results by combining 
voxel-based morphometry and voxel-based relaxometry. Neuroimage 25, 287-293.

Steel RM, Bastin ME, McConnell S, Marshall I, Cunningham-Owens DG, Lawrie SM, Johnstone EC, Best JJ (2001). Diffusion tensor imaging (DTI) and proton magnetic resonance spectroscopy (1H MRS) in schizophrenic subjects and normal controls. Psychiatry Research 106, 161-170.

Styner MA, Charles HC, Park J, Guerig G (2002). Multisite Validation of Image Analysis Methods: Assessing Intra- and Intersite Variability. Image Processing: USA.

Sun Z, Wang F, Cui L, Breeze J, Du X, Wang X, Cong Z, Zhang H, Li B, Hong N, Zhang D (2003). Abnormal anterior cingulum in patients with schizophrenia: a diffusion tensor imaging study. Neuroreport 14, 1833-1836.

Szeszko PR, Ardekani BA, Ashtari M, Kumra S, Robinson DG, Sevy S, Gunduz-Bruce H, Malhotra AK, Kane JM, Bilder RM, Lim KO (2005). White matter abnormalities in first-episode schizophrenia or schizoaffective disorder: a diffusion tensor imaging study. American Journal of Psychiatry 162, 602-605.

Szeszko PR, Vogel J, Ashtari M, Malhotra AK, Bates J, Kane JM, Bilder RM, Frevert T, Lim K (2003). Sex differences in frontal lobe white matter microstructure: a DTI study. Neuroreport 14, 2469-2473.
Thompson PM, Giedd JN, Woods RP, MacDonald D, Evans AC, Toga AW (2000). Growth patterns in the developing brain detected by using continuum mechanical tensor maps. Nature 404, 190-193.

Thompson PM, Vidal C, Giedd JN, Gochman P, Blumenthal J, Nicolson R, Toga AW, Rapoport JL (2001). Mapping adolescent brain change reveals dynamic wave of accelerated gray matter loss in very early-onset schizophrenia. Proceedings of the National Academy of Sciences of the United States of America 98, 11650-11655.

Weinberger DR, Lipska BK (1995). Cortical maldevelopment, anti-psychotic drugs, and schizophrenia: a search for common ground. Schizophrenia Research 16, 87-110.

Woodruff PW, Wright IC, Shuriquie N, Russouw H, Rushe T, Howard RJ, Graves M, Bullmore ET, Murray RM (1997). Structural brain abnormalities in male schizophrenics reflect fronto-temporal dissociation. Psychological Medicine 27, 1257-1266.

Wright IC, Rabe-Hesketh S, Woodruff PW, David AS, Murray RM, Bullmore ET (2000). Meta-analysis of regional brain volumes in schizophrenia. American Journal of Psychiatry 157, 16-25.

Wright IC, Sharma T, Ellison ZR, McGuire PK, Friston KJ, Brammer MJ, Murray PM, Bullmore ET (1999). Supraregional brain systems and the neuropathology of schizophrenia. Cerebral Cortex 9, 366-378. 